\title{
Analisis Strategi Pemberitaan Media Alternatif untuk Isu-Isu Berkaitan Dengan Kekerasan Pada Perempuan (Studi Kasus Magdalene Sebagai Media Online)
}

\author{
Della Resita, Ahmad Junaidi \\ dellaresitaa@gmail.com,Ahmadd@fikom.untar.ac.id \\ Fakultas Ilmu Komunikasi Universitas Tarumanagara
}

\begin{abstract}
The online media is divided into mainstream media and alternative media. As discussed, alternative media have differences with the mainstream media. Alternative media that supports non-commercial and anti-commercial opposition. One alternative media is Magdalena as an online media. Magdalena discusses the issue of women, LGBT, equality, relationships, dating, etc. Magdalena criticized the media for using sexist sentences or language in reporting. The formulation of the problem from this research is the strategy carried out by Magdalena as an alternative media on the issue of violence against women. The purpose of this study is to study what news strategies are carried out by Magdalena as online media that can be accepted and owned by readers. The study used descriptive research with a case study method. The subject in this study was Magdalena as an alternative media and the object of research was the news strategy carried out by Magdalene. Methods of collecting data by interviewing informants and literature studies. The results of this study are that Magdalena conducts a news strategy by creating diverse content by updating content, displaying a more attractive website, using popular language so that readers are interested in reading. Magdalena also makes branding to outside institutions to be better known and to promote through social media to attract readers.
\end{abstract}

Keywords: online media, reporting strategy, alternative media

\begin{abstract}
Abstrak
Media online dibagi menjadi media mainstream dan media alternatif. Media alternatif memiliki perbedaan dengan media mainstream. Media alternatif cenderung bersifat noncomercial dan bertujuan melawan hegemoni serta membela kaum minoritas. Salah satu media alternatif adalah Magdalene. Magdalene merupakan media online yang membahas mengenai isu perempuan, LGBT, kesetaraan, relationship, dating, dsb. Magdalene banyak melakukan kritik terhadap media yang menggunakan kalimat maupun bahasa yang seksis dalam melakukan pemberitaan. Penelitian ini bermaksud mengetahui bagaimana strategi Magdalene sebagai media alternatif terhadap isu kekerasan terhadap perempuan. Penelitian ini menggunakan penelitian deskriptif dengan metode studi kasus. Subjek dalam penelitian ini adalah Magdalene sebagai media alternatif dan objek penelitian adalah strategi pemberitaan yang dilakukan oleh Magdalene. Peneliti melakukan wawancara kepada para informan dan studi kepustakaan. Penelitian menunjukkan bahwa Magdalene melakukan strategi pemberitaan dengan cara membuat konten yang beragam dengan selalu memperbaharui konten, menampilkan tampilan website yang lebih menarik, penggunaan bahasa populer agar pembaca jadi lebih tertarik untuk membaca. Magdalene juga melakukan branding kepada lembaga luar agar lebih dikenal dan melakukan promosi melalui media sosial untuk menarik pembaca.
\end{abstract}

Kata Kunci: media online, media alternatif, strategi pemberitaan 


\section{Pendahuluan}

Berkembangnya teknologi informasi semenjak akhir milenium kedua telah menyebabkan sejumlah perubahan mendasar dalam kehidupan masnusia masa kini. Perubahan tersebut muncul seiring lahirnya mekanisme baru dalam berkomunikasi yang ditandai dengan penggunaan multimedia dimana teks, suara, gambar atau grafis dapat diakses ke dalam satu perangkat media.

Awal mula muncul internet menurut catatan Mc Millan (2004) masyarakat waktu itu masih mengidentikkannya sebagai "tools" alias alat semata dan bukan sebagai media tersendiri yang memiliki kemampuan interaktif. Namun, berbeda dengan saat ini. Internet menjadi sangat berpengaruh bagi kehidupan sehari - hari.

Hal ini pun ikut berdampak terhadap pemberitaan melalui online. Setiap orang lebih memilih membaca atau mendapatkan informasi melalui media yang sifatnya online karena lebih mudah. Media cetak memerlukan biaya untuk berlangganan setiap hari dalam mengkonsumsi informasi. Dengan adanya media online mencari berita tidak harus bayar dengan meng-click saja bahkan bisa diakses kapan pun dan dimana pun. Media online yang ditawarkan menjadi lebih efisien dan efektif. Hal ini juga yang menyebabkan persaingan menjadi sangat kuat.

Media alternatif adalah bentuk media yang berbeda dari bentuk media yang dominan dari segi konten, cara produksi, ataupun cara distribusi mereka. Media alternatif di Indonesia sangat banyak diantaranya Marsinah yang menyuarakan kaum buruh perempuan, SEJUK membahas mengenai keseberagaman, Magdalene yang berfokus pada keberagaman terutama berkaitan dengan isu-isu perempuan. Media alternatif ini memiliki tujuan, diantaranya menyuarakan suara bagi kaum minoritas, tidak populer dan berbeda dengan pendapat kebanyakkan dan mendapatkan pembaca agar banyak yang mengetahui. Mereka mengharapkan adanya para pengunjung yang tertarik untuk membaca isi konten berita tersebut. Namun persaingan sangat ketat. Media online yang dalam pemberitaannya membahas mengenai isu-isu perempuan, keberagaman. Jika dibandingkan dengan media yang ada sekarang bisa dibilang kurang populer bagi kebanyakkan orang. Walaupun begitu Magdalene tetap memiliki target pembaca yang diharapkan dapat sampai kepada pembaca setiap pesan yang diharapkan.

Magdalene sebagai media alternatif tentunya berharap agar dapat memberikan pemahaman kepada masyakarat mengenai perbedaan. Di tengah masyarakat Indonesia yang semakin bersikap intoleran, Magdalene ingin menyuarakan kepada para pembaca agar dapat bersikap toleransi terutama pada kaum perempuan. Kaum perempuan pada saat ini masih menjadi pelecehan seksual dan dijadikan sebagai kaum nomor dua dan terutama menjadi korban kekerasan. Perempuan yang menjadi korban kekerasan tidak hanya terjadi melalui fisik saja, namun juga melalui verbal. Ini sangat tidaklah nyaman bagi perempuan. Kebanyakkan perempuan yang mengalami, lebih banyak bungkam. Dalam hal ini Magdalene menjadi saluran bagi perempuan untuk menceritakan permasalahan yang dihadapinya. Namun, sangat disayangkan media alternatif memang kurang populer dan kurang menarik dibandingkan dengan mainstream. Maka dari itulah Magdelene memerlukan strategi pemberitaan dan melakukan strategi tersebut agar dapat bertahan hingga saat ini.

Penelitian terdahulu yang dilakukan oleh Mutiara Hartika (2018) mengenai Strategi Pemberitaan (LKBN) Antara Biro Riau Dalam Menghadapi Persaingan Dengan Media Online membahas mengenai strategi pemberitaan Antara Biro Riau dalam menghadapi persaingan dengan media online lain yang mulai bermunculan. 

pengumpulan data yang digunakan. Penelitian kualitatif yang dilakukan oleh adalah kualitatif deksriptif. Berdasarkan metode yang digunakan, akan menjelaskan mengenai strategi pemberitaan yang dilakukan oleh magdalene sebagai media alternatif melalui wawancara yang dilakukan. Subjek dalam penelitian ini adalah Magdalene sebagai media alternatif. Objek penelitian dalam penelitian ini adalah berkaitan dengan strategi pemberitaan yang dilakukan oleh magdalene sebagai media alternatif yang memberitakan mengenai isu kekerasan pada perempuan. Metode pengumpulan data yang dilakukan adalah dengan melakukan wawancara secara mendalam dengan 6 informan yaitu dari para pembaca magdalene dan redaktur pelaksana serta wartawan di Magdalene.

\section{Hasil Temuan dan Diskusi}

\section{Media online}

Dalam Pedoman Pemberitaan Media Siber yang dibuat oleh Dewan Pers pada 2012, Media Siber adalah segala bentuk media yang menggunakan wahana internet dan melaksanakan kegiatan jurnalistik, serta memenuhi persyaratan Undang-Undang Pers dan Standar Perusahaan Pers yang ditetapkan oleh Dewan Pers. Dalam aturan ini juga diatur tentang User Generated Content yaitu segal isi yang dibuat dan atau dipublikasikan oleh pengguna medai siber, antara lain, artikel, gambar, komentar, suara, video dan berbagai bentuk unggahan yang melekat pada media siber, seperti blog, forum, komentar pembaca atau pemirsa, dan bentuk lain. Magdalene sebagai media online dan bukan print media dengan adanya website yang dapat diakses secara online tanpa harus membelinya dalam bentuk cetak. Sebagai media online magdelene mengisi setiap pemberitaan secara online yang dapat diakses oleh para pembaca dengan mudah. Setiap orang dapat mengakses beritanya dimana pun dan kapan pun.

\section{Media alternatif}

Magdalene ini termasuk ke dalam bagian media alternatif yang sifatnya lebih terfokus pada suatu pemberitaan yang dibahas. Media alternatif adalah bentuk media yang berbeda dari media yang dominan dari segi konten,cara produksi ataupun cara produksi mereka. Magdalene dalam memberitakan sebuah pemberitaannya terfokus untuk membela para kaum minoritas terbukti dengan mengambil isu perempuan yang masih sangat minim. Tidak hanya isu yang berkaitan dengan isu perempuan saja tetapi juga kaum LGBT, kaum feminist, toleransi agama. Magdalene yang merupakan media alternatif tidak mendapatkan banyak keuntungan dari segi keuangan. Tidak hanya itu hal ini juga membuat Magdalene tidak populer seperti media mainstream pada umumnya. Jika media mainstream sangat mudah untuk mendapatkan pembacanya dan beriklan tetapi itu tidak mudah bagi semua media alternatif. Walaupun setiap pembahasan yang dibahas oleh media alternatif cenderung berbeda dan tidak banyak media online yang membahas berita seperti ini terutama tentang isu -isu perempuan.

\section{Pemberitan mengenai kekerasan terhadap perempuan}

Magdalene yang memberikan suara bagi kaum minoritas ini memilih mengangkat isu perempuan. Isu perempuan masih sangat jarang untuk dibahas secara mendetail. Magdalene membahas ini sebagai pembelaan terhadap kaum perempuan yang suaranya masih terbungkam. Perempuan juga memiliki banyak pengalaman yang tidak dapat dibagikan dan tidak memiliki ruang untuk menyuarakan suara nya dan Magdalene hadir sebagai sebuah media untuk menyuarakannya. magdalene yang 
membahas mengenai isu kekerasan pada perempuan ini membuat para pembaca memahami bahwa pemberitaan mengenai perempuan sangat berguna untuk mendapatkan pengetahuan yang baru.

Pembahasan yang dibahas oleh magdalene mengenai isu perempuan masih sangat relevan untuk diberitakan pada saat ini. Berdasarkan apa yang terjadi akhirakhir ini tentang bagaimana perempuan menjadi korban kekerasan yang tidak terduga dan membuat para pembaca pun memahami bahwa kekerasan terhadap perempuan masih banyak terjadi saat ini.

Strategi pemberitaan yang dilakukan oleh Magdalene

Strategi pemberitaan adalah cara yang dilakukan dari suatu organisasi atau kelompok dalam proses pembuatan berita, dimulai dari liputan suatu peristiwa, menulis berita, mengedit berita hingga menyebarkan berita. Strategi pemberitaan digunakan oleh kelompok, organisasi maupun instansi guna mencapai tujuan yang ingin diraih oleh kelompok, organisasi maupun instansi tersebut. Dengan begitu, kelompok, organisasi maupun instansi tersebut mendapat kepercayaan dari para pembacanya.

Magdalene melakukan banyak cara dalam strategi pemberitaan agar tetap bertahan. Magdalene yang sudah berdiri sejak 2013 hingga saat ini, mengalami banyak proses untuk berdiri sebagai media online. Ketidakpuasan para pendiri terhadap pemberitaan media mainstream membuat para pendiri akhirnya memutuskan untuk membuat media online. Namun dikarenakan memerlukan biaya dan sources sehingga mereka memutuskan untuk membuat sebuah berita yang lebih terfokus. Akhirnya terbentuklah Magdalene yang merupakan media alternatif. Media alternatif adalah bentuk media yang berbeda dari media yang dominan dari segi konten, cara produksi ataupun cara produksi mereka.

Magdalene menerapkan hal ini sebagai media alternatif yaitu dengan mengambil isu perempuan salah satunya mengenai kekerasan pada perempuan. Isu perempuan yang ada menjadi fokus utama bagi magadelene untuk dibahas walaupun banyak hak minoritas lain yang dibahas oleh magdalene seperti LGBT, minoritas agama dsbnya. Fokus yang diambil oleh magdalene ini membuatnya masih ada hingga saat ini.

Magdalene sebagai media alternatif berusaha memberikan pemahaman kepada para pembaca bahwa isu perempuan tidak hanya sekedar pada saat ada event tertentu seperti kartini, hari ibu atau sedang ada skandal atau hal seperti fashion tetapi juga perempuan merupakan mahluk yang hebat dan kuat yang sama dengan laki-laki. Pemahaman yang diberikan dan disampaikan oleh Magdalene berhasil membuat para pembacanya berhasil memahami apa yang ingin disampaikan oleh para pembacanya.

Magdalene memberikan ruang untuk bersuara dengan tulisan yang dibuat oleh pembaca melalui website yang membuat orang lain bisa bertanya dan melakukan diskusi satu dengan yang lain, melalui ask magde. Tujuannya adalah setiap orang bisa berdiskusi dan memberikan suaranya yang tidak dapat tersampaikan melalui magdalene sebagai penyalur suara mereka. Seringkali perempuan yang menjadi korban tidak dapat menyuarakan apa yang mereka rasakan dikarenakan rasa malu, disalahkan oleh pihak lain yang membuatnya memilih untuk berdiam diri saja.

Magdalene juga banyak melakukan diskusi untuk membahas mengenai isu yang terupdate pada saat ini untuk diberitakan. Diskusi ini dilakukan untuk membuat magdalene tetap memberitakan terbaru yang sesuai dengan kejadian yang ada saat ini. Setiap orang yang bekerja di Magdalene ini melakukan pertemuan sebulan sekali untuk brainstroming. Isu perempuan berkaitan dengan feminisme. Feminisme sendiri 
dianggap sebagai paham yang membenci kaum laki-laki, ateis, tidak percaya pernikahan dsbnya. Padahal kenyataannya feminisme ini bukan menganggap laki laki lebih rendah tetapi lebih menganggap pada kesetaraan antar laki - laki dengan perempuan.

Magdalene selalu update dengan berita terkini sebagai daya tarik bagi untuk pembacanya. Ini menunjukkan bahwa setiap pemberitaan yang dibawakan oleh Magdalene relevan dengan keadaan yang sedang terjadi saat ini. Para pembaca menjadi tidak bosan dengan pemberitaan yang dibawakan terutama Magdalene sangat mengedepankan bahasa - bahasa yang mudah dimengerti. Magdalene juga banyak terlibat dengan para komunitas lain. Dengan melakukan hal ini maka magdalene dapat membuat magdalene semakin maju dan dikenal oleh masyarakat luas.

Dari strategi tersebut maka magdalene pun mendapatkan khalayak yang membaca website mereka. Walaupun target utama magdalene adalah kaum urban dan educated, namun ternyata magdalane mampu menarik khalayak pria dan perempuan yang masih remaja untuk membaca pemberitaan mereka. Selain itu juga, banyak diantara mereka juga ingin berbagi pengalaman mereka masing- masing kepada magdalene. Ini menunjukkan bahwa magdalene sebagai media online berhasil membuat pembaca memahami apa yang ingin disampaikan kepada khalayak luas. Bahkan banyak juga dari mereka yang melakukan tanya jawab. Tanya jawab yang dilakukan ini memberikan wadah kepada mereka yang tidak memiliki wadah untuk bertanya dan menyampaikan pengalaman masing-masing. Mereka yang bertanya diantaranya mereka yang masih remaja.

Ketika Magdalene memutuskan untuk menjadi media alternatif, bukanlah hal yang mudah untuk mendapatkan khalayak. Hal ini dikarenakan tidak memiliki uang dan sources yang cukup sehingga harus berusaha dan memperjuangkannya sendiri. Para pendiri saat mendirikan magdalene hingga mampu bertahan hingga saat ini, harus berjuang sendiri dan mendapatkan dukungan dari teman-teman dan mengajak komunitas lain. Dengan mengajak komunitas lain bekerja sama ini merupakan bagian dari strategi yang dilakukan oleh Magdalene. Ini juga berhasil dilakukan oleh Magdalene karena dengan mengajak komunitas lain untuk bekerja sama maka akan semakin banyak juga ide atau gagasan yang dimiliki oleh Magdalene.

Tidak hanya itu, Magdalene juga semakin memiliki jaringan yang luas dalam melakukan pemberitaan mengenai isu-isu perempuan. Semakin luas pemberitaan yang dilakukan semakin menunjukkan bahwa Magdalene memiliki ruang untuk menyuarakan mereka yang suaranya tidak didengarkan dan terbungkam. Strategi ini juga yang menjadikan Magdalene tetap bertahan dan ada hingga saat ini. hal ini pun dapat dilihat dari para pembaca yang memahami apa yang ingin disampaikan oleh Magdalene sebagai media alternatif.

\section{Simpulan}

Magdalene mampu bertahan sebagai media alternatif dalam memberitakan isuisu tentang kekerasan perempuan. Berdasarkan penelitian yang dilakukan dengan melakukan wawancara dengan para informan Magdalene mampu bertahan hingga saat ini dan berkembang dengan mendapatkan tambahan khalayak. Penambahan khalayak ini membuktikan bahwa Magdalene mampu bertahan dari 2013 hingga saat ini dan diterima oleh para pembacanya. sedangkan dari segi pembacanya pun mereka memahami mengenai isu yang disampaikan oleh Magdalene mengenai kekerasan yang 
terjadi terhadap perempuan. Magdalene pun sebagai media tetap konsisten dalam melakukan pemberitaan dan tidak berubah untuk tetap menyuarakan isu perempuan.

Magdalene memiliki strategi ketika melakukan pemberitaan yang berkaitan dengan isu-isu kekerasan perempuan. Setelah melakukan analisis strategi pemberitaan yang dilakukan oleh Magdalene sebagai media alternatif, dapat disimpulkan bahwa Magdalene sebagai objek penelitian melakukan strategi yaitu dengan menggunakan bahasa-bahasa yang populer, memberitakan berita ter-update, memperbaharui website, menambahkan multimedia seperti podcast, bekerja sama dengan lembaga dan komunitas lain. Selain itu berita yang diberitakan oleh Magdalene juga bersifat detail dan terfokus dibandingkan dengan media mainstream pada umumnya.

Peneliti menyimpulkan bahwa strategi pemberitaan yang dilakukan oleh magdalene dengan bahasa-bahasa yang populer, memberitakan berita ter-update, memperbaharui website, menambahkan multimedia, seperti gambar, podcast, bekerja sama dengan lembaga dan komunitas lain ini sangat berpengaruh untuk mempertahankan Magdalene hingga saat ini.

Dengan menggunakan strategi seperti pembaca lebih mudah untuk memahami apa yang disampaikan oleh magdalene sebagai media alternatif yang dalam pemberitaannya membahas mengenai isu perempuan salah satunya adalah kekerasan terhadap perempuan. Hal ini pun terbukti dengan bertahan magdalene mulai dari 2013 hingga saat ini serta bertambahnya para pembaca dan yang mengirimkan pengalaman yang dialami oleh penulis kepada magdalene.

\section{Ucapan Terima Kasih}

Penulis mengucapkan terima kasih kepada pihak-pihak yang telah membantu dalam proses penelitian hingga dipublikasikan, terutama kepada narasumber yang telah bersedia meluangkan waktu untuk kerjasamanya selama proses penelitian ini berlangsung.

\section{Daftar Pustaka}

Alexander Aprita Ermando Drajad / Yohanes Widodo. (2014). Verifikasi Pemberitaan Media Online (Studi Kasus Proses Penerapan Pedoman Pemberitaan Media Siber Pemberitaan Florence Sihombing di Detik.com dan Kompas.com Periode Agustus - September 2014). E-Journal UAJY. Universitas Atma Jaya Yogyakarta, 15

Ayu Erivah Rossy dan Umaimah Wahid. Analisis Isi Kekerasan Seksual Dalam Pemberitaan Media Online Detik.Com, Jurnal Komunikasi. Universitas Budi Luhur

Moleong, Lexy J. (2007). Metodologi Penelitian Kualitatif. Bandung: Remaja Rosdakarya.

Mutiara Hatika. (2018). Strategi Pemberitaan (Lkbn) Antara Biro Riau Dalam Menghadapi Persaingan Dengan Media Online. E-Journal Uajy. Universitas Riau, Pekan Baru, 13 
Vol. 2, No. 2, Desember 2018, Hal 269-276

Rini Darmastuti. Media Alternatif, Masa Depan Media Indonesia. Repository. Universitas Kristen Satya Wacana, Salatiga, 18

Sugiyono. (2007). Metode Penelitian Kuantitatif Kualitatif dan R\&D. Bandung: Elfabeta.

Sujarweni. V. Wiratna. (2014). Metodologi Penelitian (lengkap,praktis dan mudah dipahami). Yogyakarta: Pustakabarupress 